\title{
O Pensamento Freireano como Superação de Desafios do Ensino para o SUS
}

\author{
Freirean Thinking how Overcoming to \\ Education in SUS's Challenges
}

Rodrigo Otávio Moretti-Pires ${ }^{I}$

\section{PALAVRAS-CHAVE: \\ - Educação Médica; \\ - Educação em Saúde; \\ - Saúde da Família; \\ - Paulo Freire.}

KEYWORDS:

- Medical Education;

- Health Education;

- Family Health;

- Paulo Freire.

Recebido em: 12/04/2010

Encaminhado em: 17/01/2011

Aprovado em: 21/05/2012

\section{RESUMO:}

A construção histórica do Sistema Único de Saúde (SUS) levou à adoção da Saúde da Família como estratégia central para diminuir a distância entre o ideal e o real. A formação dos profissionais é um desafio nesse contexto. Diversas iniciativas para mudanças significativas foram implementadas. $O$ presente ensaio objetiva investigar esse contex to e mostrar a adequação da teoria freireana na construção de modelos pedagógicos crítico-reflexivos, com excelências técnica e social, mas em uma perspectiva ampliada dos processos de saúde.

\section{ABSTRACT:}

The Single Health System historical building get to Family Health adoption how central strategy to do minor distance between ideal and real. Professional formation is one challenge in this context. Many initiatives to significant changes were implemented. The assay's aim is to investigated this context and to show the adequacies from freirean theory in the building of critical reflexive pedagogic models, with technical and social excellences, but in applied perspective to health process. 


\section{INTRODUÇÃO}

A importância de se investigar e criar conhecimento científico repousa na capacidade do homem em melhorar o mundo em que vive. Modificar um sistema de saúde para servir efetivamente à população também se insere nessa perspectiva, da mesma forma que promover mudanças no ensino superior em saúde.

É nesse sentido que se opta pela perspectiva de Paulo Freire e de seus trabalhos para a construção do presente ensaio: a articulação existente entre formação dos profissionais da saúde, Sistema Único de Saúde (SUS) e as demandas dos usuários do sistema, representantes da vida vivida, tanto no acesso à assistência como no fazer valer de seus direitos como cidadãos brasileiros.

Nos últimos anos, essa discussão tem ganhado atenção significativa de diversos setores da sociedade, do Estado e da academia. Existem implicações práticas e políticas relevantes, por se imergir em amplo espaço de articulação teórica e construção científica referente ao papel e potencialidades do ensino superior como responsável pelo futuro profissional que se inserirá no SUS.

Esse contexto traduz uma perspectiva muito maior do que a inicialmente aparente: a necessidade de adequação entre formação e vida real, entre teoria e prática, entre teorização e aplicabilidade factual.

Para o presente trabalho, optou-se em promover uma revisão narrativa sobre o transcurso do SUS, a implementação do Programa de Saúde da Família (PSF) e a formação do enfermeiro, do médico e do odontólogo. Objetiva-se discutir a formação universitária e sua adequação ao sistema de saúde, sustentando-se na perspectiva teórica de Paulo Freire.

Na tentativa de dar conta dos aspectos propostos, o desenvolvimento deste artigo divide-se em três partes. Inicialmente promoveu-se uma revisão da dimensão histórica do SUS, como forma de contextualização da estrutura macro pertinente à temática. Os problemas da articulação entre o SUS e a formação universitária pertencem à segunda parte. A cargo da última parte, os pressupostos das principais obras de Paulo Freire e sua pertinência em relação à problemática investigada são apresentados.

\section{DESENVOLVIMENTO}

\section{O Nó da Estrutura: o Sistema Único de Saúde e a Saúde da Família}

A questão do direito aos serviços de saúde, mantidos pelo Estado, tem diferentes fases na história do Brasil. Parte da intervenção estatal em epidemias nos munícipes de cidades portuárias, chegando à garantia legal de acesso universal, equânime e integral, constitucionalmente instituídos como direito e manifestação de cidadania ${ }^{1,2}$.

No entanto, os princípios e diretrizes do SUS não retratam a realidade operacional do sistema, dada a grande demanda ocasionada por fatores socioeconômicos e sucateamento histórico do serviço público de saúde ${ }^{3,4}$. Esse panorama permeou as discussões da área da saúde do início da década de 1990, quando então se primou pela reformulação da atenção primária no País, não apenas em termos da organização e estrutura, preconizando-se um novo enfoque e participação dos diversos atores sociais nos serviços, quando o usuário começa a ter voz $^{4-6}$.

O primeiro dos nós apresentados no presente ensaio refere-se a esse contexto. Durante o processo de implantação do SUS, ficaram patentes as lacunas em termos de universalidade do acesso, equidade na atenção e integralidade junto às necessidades do usuário. O quadro instituído direcionou o enfoque no sentido da ampliação dos serviços de saúde, haja vista que, por anos, o Estado investiu na compra de serviços privados para os trabalhadores formais, e a estrutura utilizada pelo SUS não conseguia dar conta da grande demanda ${ }^{5-6}$.

Na tentativa de ampliar o acesso, e com isso tornar o SUS legal mais próximo do SUS factual, em 1992 implementou-se o Programa de Agentes Comunitários de Saúde (Pacs). É criada uma nova equipe e processo de trabalho, com agentes comunitários de saúde - com função de estabelecer uma ponte entre os serviços e a comunidade - supervisionados pelo enfermeiro.

A iniciativa do Ministério da Saúde foi mais audaciosa em 1994: levar uma equipe mínima de técnicos assistidos pelo médico e pelo enfermeiro, em uma lógica muito compatível aos princípios norteadores do sistema ${ }^{7}$. Entre as inovações, estabelecem-se diretrizes para o processo de trabalho, tais como o planejamento na atenção primária com foco na família; a imersão dos profissionais no trabalho em equipe; a priorização da promoção da saúde, e não apenas das ações curativas; o vínculo com a comunidade; e a ação intersetorial da equipe nos diversos seguimentos da comunidade. Trata-se da reorganização dos serviços de atenção primária para uma atenção em saúde além dos determinantes biológicos e na lógica do trabalho coletivo em saúde, não mais para o trabalho individualizado dos profissionais dos diversos setores ${ }^{6-9}$.

O primeiro dos nós que se defende no presente ensaio refere-se à estrutura encontrada nos serviços. A passividade desenvolvida por vezes no processo de ensino-aprendizagem dos acadêmicos da área da saúde, através do talhe bancário e da priorização da memorização de conteúdos, acrescida à pouca articulação do processo educacional ao cotidiano dos 
serviços e suas dificuldades, reflete-se na formação de um profissional da saúde que apresenta dificuldades em utilizar-se da criatividade para o enfrentamento das mazelas que a estrutura do SUS/PSF pode apresentar. Freire conceitua que a realidade “(...) não pode, por ser histórica tal como os homens que a criam, transformar-se por si só. Os homens que a criam são os mesmos que podem prosseguir transformando-a" ${ }^{10}$ (p. 18).

Um dos maiores desafios em se formar para o SUS é propiciar aos educandos ferramentas reflexivas que lhes possibilitem intervir no contexto sociocultural e político em que as unidades de saúde estão imersas. Sem uma estrutura adequada dos serviços, é de se esperar que os profissionais se engajem em negociações com diversos atores sociais, extrapolando o modelo clínico-assistencial de atuação, agindo como transformadores sociais. No entanto, essa forma de se exercer as diversas profissões da saúde não tem consonância com o modelo universitário vigente, em que pesa o importante foco nos conhecimentos técnicos.

Entendo práxis a partir de Freire, ou seja, como a ação consciente para transformar aquilo que está em aquilo que deve ser, as insuficiências e problemas estruturais do SUS não justificam por si só a passividade profissional diante dos desafios para transformá-lo no sistema preconizado. Freire sustenta que: "É exatamente esta capacidade de atuar, operar, de transformar a realidade de acordo com finalidades propostas pelo homem, qual está associada sua capacidade de refletir, que o faz um ser da práxis"10 (p. 17).

\section{O Nó Da Formação: Fragmentação do Corpo e da Equipe Multiprofissional}

Por mais que o PSF preconize a proximidade entre a enfermagem, a medicina e a odontologia, por mais que o enfoque para a ação em saúde esteja na realidade e na complexidade da vida do paciente, os ganhos principais com a implementação do PSF são em termos de universalidade e equidade ${ }^{7}$. No entanto, resta lacuna quanto à integralidade, uma vez que os profissionais apresentam grande dificuldade em atuar em equipe multidisciplinar, assim como para mudar sua visão e atuação clínica, ainda priorizando a doença em vez da intervenção junto aos determinantes do processo saúde-doença-9;11-12.

A inadequação dos profissionais ao novo modelo toma como emblema privilegiado a questão da postura humanizada e da valorização das inter-relações humanas. Essa problemática se refere tanto às relações entre os profissionais, destes enquanto equipe, e entre esta e os pacientes. Há a manutenção das práticas tradicionais, pautadas no modelo biomédico, mesmo que em uma "roupagem" de Saúde da Família, incompatível com sua proposta ${ }^{12-13}$.
Dada a proeminência da inadequação entre o discurso oficial para a Saúde da Família e sua prática, foram denunciadas dificuldades das Instituições de Ensino Superior em formar profissionais com perfil adequado ao cotidiano idealizado para as equipes de Saúde da Família, exigindo mudanças na formação de enfermeiros, médicos e odontólogos ${ }^{17}$. Os resultados de diversas pesquisas apontavam que, para a Saúde da Família se efetivar, a formação para a humanização do atendimento e a ação intersetorial deveriam estar presentes no curso de graduação dos profissionais da equipe ${ }^{13-15}$.

É patente na literatura o panorama de incoerência entre o perfil do profissional da saúde egresso das Instituições de Ensino Superior e a adequação ao que carece o SUS, de forma que o governo federal instituiu, por meio dos Ministérios da Saúde e da Educação, iniciativa para a reformulação da formação em enfermagem, medicina e odontologia no Brasil ${ }^{16}$. No entanto, diversos problemas foram encontrados na aderência dos cursos à iniciativa ${ }^{17}$, assim como da efetividade desta junto aos egressos que atuam em Saúde da Família ${ }^{14-15}$.

Avanços importantes foram conseguidos a partir de iniciativas salutares do Estado, tais como o Programa Nacional de Reorientação da Formação Profissional em Saúde (Pró-Saúde I e II $)^{16}$ e Programa de Educação para o Trabalho para a Saúde (PET-Saúde) $)^{18}$ - que em seu escopo incidem sobre a formação universitária - ao lado de outros, como o Programa Nacional de Telessaúde e a Universidade Aberta do SUS (UNA-SUS) $^{19}$ - que atuam junto aos profissionais egressos inseridos nos serviços.

A despeito das conquistas, um ponto nevrálgico ainda é preterido: o aprender em conjunto com as demais categorias profissionais. Ao comparar a atuação em equipe de profissionais do PSF egressos de Universidades que passaram por adequação às Diretrizes Nacionais Curriculares e profissionais de nível hospitalar oriundos de modelos tradicionais de ensino, Moretti-Pires \& Campos $^{14}$ observaram, a partir das informações sobre os currículos dadas pelos próprios depoentes, poucas diferenças, levantando a hipótese de que, mesmo com a reformulação do currículo, as três formações universitárias que atuam no PSF ainda têm seus currículos desarticulados entre si, não aprendendo a articular os saberes na prática dos serviços.

Em termos freireanos, a educação deve propiciar espaços de interface de conhecimento e diálogo entre os diversos saberes com a vida vivida dos educandos, levando o ser humano a relacionar-se com homens de realidades distintas e com o mundo, em um processo em que "A educação deve ser desinibidora e não restritiva. (...) Caso contrário domesticamos, o que significa a negação da educação" ${ }^{\prime 10}$ (p. 32). 
Teoricamente, o modelo pedagógico dos cursos deveria voltar-se a uma visão holística dos pacientes, cujo espaço privilegiado de formação deixaria de ser os núcleos ultraespecializados de conhecimentos hospitalares, para ser a atenção primária e o profissional generalista exigido ${ }^{16}$. Mais do que os serviços de saúde, a determinação social do processo saúde-doença se dá no âmbito do contexto sociocultural e econômico dos usuários do SUS, em clara necessidade de imersão em seu mundo. Freire argumenta que a educação transformadora torna em humana a ação, de simples ato mecânico — tão característico do enfoque biomédico - em ato pensado, crítico-social, com um sentido a serviço dos homens. Trata-se de "(...) um compromisso com o mundo, que deve ser humanizado para a humanização dos homens, responsabilidade com estes, com a história"10(p. 79)

A questão da dificuldade do enfermeiro, do médico e/ ou do odontólogo em lidar com o paciente horizontalmente e como ser humano, de pensar o seu entorno sociocultural, de trabalhar junto a outros trabalhadores - tão profissionais e humanos como ele próprio, remetem à ideia de atuação não humanizada em saúde, desfragmentada da visão apresentada anteriormente $\mathrm{e}^{20}$.

A literatura acerca do ensino de enfermagem, de medicina e de odontologia converge para a existência de problemas na articulação da formação no novo contexto de Saúde da Família efetiva, sendo necessário o debate dos papéis dos docentes, dos discentes, da Universidade e do SUS nessa problemática, já que o aumentar a oferta de serviços não acarretou necessariamente em aumento no grau de coerência entre o que o SUS é e o que deveria ser por seus princípios ${ }^{21-26}$.

\section{O Desfazer dos Nós: o Pensamento Freireano e o Ensino Superior em Saúde}

$\mathrm{Na}$ concepção de Gagottii ${ }^{27}$, os pressupostos do universo conceitual freireano vão além da simples teorização intelectual acadêmica, jamais distante da vida vivida, do homem real ${ }^{27}$. Nesse sentido, trabalhar a questão da formação do profissional da saúde é investigar em sua origem e observar sua articulação além da academia. Envolve o próprio ser humano e o processo ensino/aprendizado a que se submeteu na profissionalização, e que não é uma dimensão dissociada da sociedade ${ }^{27}$.

Nessa análise do processo de formação, deve ser considerado que a educação é um ato político ${ }^{43}$ dentro dos pressupostos freireanos, sendo um espaço privilegiado à mudança em sociedade, uma vez que esta a constitui ${ }^{28}$ e dá seus contornos.

Há décadas a formação nessas três profissões da área da saúde se tornou mais centrada no atendimento privado, no caso da odontologia, e no hospitalar, em se tratando da en- fermagem e da medicina. Os modelos pedagógicos das Instituições de Ensino Superior primaram por essa perspectiva ${ }^{14-15}$. Historicamente, como exposto, modificou-se o direcionamento político do Sistema de Saúde, havendo necessidade de readequação do modelo pedagógico para uma nova abordagem da realidade e da assistência. No entanto, a dimensão política da educação não se dá apenas no âmbito do Estado, mas também dos demais atores, nesse caso, da opção e adequação da Universidade diante dessa demanda, dos docentes e do corpo discente perante essa proposta ${ }^{29}$.

A adequação da formação em saúde para a abordagem preconizada em Saúde da Família vai ao encontro da perspectiva de Paulo Freire para o ensino, na medida em que a educação não deve ser reduzida à capacitação tecnicista, e sim deve se referir à formação de cidadãos ${ }^{30}$, de indivíduos que consigam mais do que o fazer técnico, que pensem sobre si mesmo e sobre a sociedade em que estão inseridos ${ }^{27}$.

Outro pressuposto freireano consoante com a proposta de remodelação da formação em saúde é a necessidade de que a educação desenvolva a criatividade no educando, condição necessária para a ação transformadora da realidade ${ }^{30}$.

A perspectiva da ação em saúde que supere o paradigma biomédico é uma proposta na qual o exercício profissional deve surgir não apenas dos aspectos técnicos, mas também da reflexão e de sua aplicação, avaliando e optando por caminhos, consciente das consequências dos atos não apenas para si, mas para todos os semelhantes, de forma que a criatividade possibilite ao ser humano relacionar-se com os outros homens e com o mundo e, assim, criar sua história ${ }^{31}$.

No processo formativo do enfermeiro, do médico e do odontólogo, em uma perspectiva crítico-social, deve haver criação e recriação da realidade, em que a educação se torna instrumento de democracia, a qual só se aprende fazendo democracia ${ }^{32}$. Essa acepção pode reverter a verticalidade na relação entre os profissionais, para implementar uma equipe no sentido real, e entre esta e os usuários do serviço. Mas, para tanto, é necessário que a educaçãse assuma como libertadora, uma vez que a democracia pressupõe liberdade ${ }^{32}$.

A questão da verticalidade na relação entre profissional e usuários está fundamentalmente relacionada à problemática da humanização do atendimento. Dentro do marco teórico freireano, ao homem cabe refletir sobre si, sobre seus semelhantes e sobre o mundo onde (e com quem) está. Humanizar não é só tratar bem, como se gostaria de ser tratado. Humanizar é um ato de pensamento crítico-reflexivo ${ }^{30}$. Pressupõe exercer a técnica profissional centrada no homem, mas também exercê-la como ser humano, mais do que técnico, refletindo-se nesse ato $^{33}$ 
A educação que leva em conta a humanização entende o homem como histórico, social e complexo, postura divergente do ensino tradicional que toma o homem como "coisa", segundo Freire ${ }^{31}$. A tarefa da educação é humanizar o educando, mais do que treiná-lo como simples reprodutor de técnicas ${ }^{31}$.

E Freire vai mais longe: humanizar significa imergir-se na realidade e "só existe no engajamento com a realidade, de cujas águas os homens verdadeiramente comprometidos ficam molhados, ensopados"31 (p. 19), pensamento perfeitamente adequado à idealização do trabalho em Saúde da Família e ao conhecimento acerca da realidade na qual o profissional intervém ${ }^{5,9,15}$.

No universo conceitual freireano, a educação pode apresentar-se em duas correntes distintas e dicotômicas: a educação tradicional, "bancária" ou depositária; e a educação libertadora, crítico-reflexiva ou problematizada.

A educação tradicional é descrita por Freire como caracterizada por uma relação narradora, em que o educador disserta para os educandos conteúdos lidos/narrados ${ }^{33}$, pautando-se em "retalhos da realidade desconectados da totalidade, em que engendram e em cuja visão ganhariam significação"33 (p.57).

Para aprovação e progressão nos diversos níveis educacionais, é exigida a "memorização mecânica do conteúdo narrado. (...) a narração os transforma em 'vasilhas', em recipientes a serem 'enchidos' pelo educador. (...)"33 (p. 66). Em Freire, a denominação educação bancária refere-se a este ato de "depositar conteúdos"33 (p. 67).

Freire define educação libertadora como aquela baseada na relação educador-educandos, orientada "no sentido da humanização de $\operatorname{ambos}^{\prime 33}$ (p. 88), em que “(...) o educador convida os educandos a conhecer, a desvelar a realidade, de modo crítico" $^{\prime \prime 3}$ (p. 89). É também o modelo pedagógico "do pensar autêntico e não no sentido da doação, da entrega do saber. Sua ação deve estar infundida da profunda crença nos homens. Crença no seu poder criador"33 (p. 54).

A educação libertadora "é humanização em processo, não é uma coisa que se deposita nos homens. Não é uma palavra a mais, oca, mitificante. É práxis, que implica a ação e a reflexão dos homens sobre o mundo para transformá-lo"33 (p. 67). A educação deve se pautar no diálogo com os educandos e seus mundos, de forma que "(...) deve estar imersa na experiência histórica e concreta dos alunos(as)"32 (p. 47).

Trazendo esses conceitos à questão da formação dos profissionais da saúde, além da importância de se redefinir o modelo pedagógico dos cursos, com vistas à democracia, à humanização do educador, sua postura perante o educando deve ser repensada ${ }^{33}$. Oprimindo, se ensina opressão, enquanto o ensino com liberdade ensina libertação social.
Há necessidade de estudos que indiquem qual a postura atual do docente na Universidade, pois, conforme os educandos aprendem a postura verticalizada no trato com os educadores, apresentam dificuldades no relacionamento humanizado. A postura tradicional de professores da área não é compatível com o modelo de saúde que se deseja colocar em prática, dada a implicação da postura dos professores na formação dos futuros profissionais.

O educador deve ser coerente com suas convicções, manifestando-as em suas atitudes, de forma que, para formar cidadãos, o ensino democrático deve ser coerente com a democracia. Somente é possível ensinar ao acadêmico o respeito à voz e à vida do paciente enquanto cidadão, se a ele mesmo, acadêmico, for dada voz e respeito durante o processo de ensino-aprendizagem ${ }^{31,33}$.

A importância da valorização na educação, não apenas dos conteúdos anteriormente elaborados do ser humano, mas também da realidade e de seu potencial para fins de ensino, caminhando paralelamente e com a mesma valorização, refere-se, no pensamento freireano, ao princípio de que o ser humano não está no mundo como um local inócuo em que a vida se desenrola. O mundo está em um conjunto de relações entre homens e homens, e entre estes e o mundo, tal como é a fundamentação da Saúde da Família.

Longe de apenas transmitir conhecimentos distantes da realidade, a educação do profissional da saúde deveria se originar na reflexão "sobre o homem em suas relações com o mundo, (...) relações em que consciência e mundo se dão simultaneamente. Não há uma consciência antes disso e um mundo depois e vice-versa" ${ }^{\prime 33}$ (p. 70).

Os conhecimentos humanos, nesse contexto, são mais do que o raciocínio sobre a realidade, mas fruto e fator modulador desta ${ }^{34}$. São resultantes da interação do sujeito (homem) com o objeto (mundo), "nestas relações com a realidade e na realidade" ${ }^{\prime 33}$ (p. 105). Estas características, se negadas no ato da educação, representam desrespeito à humanidade dos discentes, como acontece quando o docente valoriza conteúdos predefinidos, ministrando-os dissociados da realidade social para discentes passivos no processo.

Ignorar essa característica do conhecimento, que é dialético e dialógico com o todo social, é descontextualizar o processo de ensino-aprendizagem de sua aplicabilidade, já que é no mundo real, com a produção pessoal de conhecimento pautado nesse mundo, que os futuros profissionais atuarão, e não em situações que simulam a realidade, falando sobre a realidade a partir de laboratórios ou condições controladas.

A proximidade do conhecimento com a realidade é imprescindível por que, segundo Freire, "na medida em que o 
homem, integrando-se nas condições de seu contexto de vida, reflete sobre elas, leva respostas aos desafios que se lhe apresentam"32 (p. 43).

No processo educativo, Freire prioriza a formação da consciência crítica do discente, caracterizada pela análise contextualizada da realidade, que, nessa compreensão, é dinâmica, podendo se modificar com o transcurso histórico e circunstancial ${ }^{27}$.

Para entender determinada realidade, a consciência crítica a examina conforme seu conhecimento prévio, mas também sobre o que o momento, o que o empírico lhe traz sobre essa realidade, que, em um segundo momento, pode não ser mais como no primeiro.

A postura contrária a essa é chamada de consciência ingê$n u a$, para a qual a realidade é estática e, dessa forma, pode ser reduzida a fórmulas e ao domínio do pensamento intelectual. Sendo assim, o conhecimento pode ser transmitido de indivíduo para indivíduo, já que há estabilidade na realidade. Tal pensamento, de cunho positivista, norteia o ensino pelo paradigma biomédico, que, transmitindo as artes dos diagnósticos e procedimentos, ensina futuros profissionais para a intervenção junto à doença individual dos usuários dos serviços. É um pensamente frágil, no mínimo, insustentável na complexidade das relações entre saúde individual e sociedade, abordagem imprescindível em Saúde da Família.

O pensamento biomédico aplicado em saúde orienta-se pela educação para a consciência ingênua, por tomar a realidade como algo estático e perceber o homem no mundo, e não com o o mundo. Há supervalorização do conhecimento intelectual e técnico, em que o educando deve "submeter-se com docilidade. É próprio dessa consciência o fatalismo, que leva ao cruzamento dos braços, à impossibilidade de fazer algo diante do poder dos fatos, sob os quais fica vencido o homem"34 (p. 104). Caracteriza-se pelo pensamento do ensino bancário.

A educação tem potencial para desenvolver a consciência crítica ou a consciência ingênua nos discentes, em conformidade com o modelo em que se dê. A vida, o homem no mundo e com o mundo são direções inerentes à educação para a consciência crítica, dado que o desenvolvimento de habilidades técnicas é necessário nas práticas assistenciais, mas não superam a importância de contextualizá-las diante da realidade e dos diversos contextos que a vida e o homem trazem.

Problematizar é trazer o ensino para a realidade e articulá-lo com esta, permitindo ao educando construir um conhecimento sólido e contextualizado, necessário ao exercício futuro profissional da saúde.

Na problematização do ensino, é fundamental o diálogo entre educador e educandos. "É uma relação horizontal (...). Nasce de uma matriz crítica e gera criticidade. (...) Só aí há comunicação. (...) O antidiálogo que implica numa relação vertical (...), é oposto a tudo isso. Não comunica. Faz comunicados ${ }^{\prime 27}$ (p. 69). Em uma postura do educador que permite a construção da educação pautada no ensino libertador, na humanização e na conscientização, possibilita-se que o futuro enfermeiro, o futuro médico e o futuro odontólogo façam de sua ação clínica uma práxis, definida por Freire como ação e reflexão sobre a realidade ${ }^{31}$. Toda e qualquer ação sem a reflexão da realidade deixa de ser práxis e torna-se ação mecânica, não humanizada ${ }^{31}$.

Essa questão sobre a práxis está entrelaçada no uso da técnica pelos profissionais. Segundo Freire, a divisão dos homens entre o mundo dos técnicos e o mundo dos outros homens é uma instância de desumanização, já que, antes de profissional, trata-se de um ser humano ${ }^{30}$

Mais do que privilégios, tornar-se profissional traz intrinsecamente responsabilidades, de acordo com o pressuposto freireano de que todo conhecimento e toda produção humana pertencem ao patrimônio cultural da humanidade. Esse pensamento justifica-se na medida em que não há homens que se constituam como tal sem relacionar-se historicamente com todos outros homens. "Todo amanhã se cria num ontem, através de um hoje. De modo que o nosso futuro baseia-se no passado e se corporifica no presente. Temos de saber o que fomos e o que somos, para saber o que seremos"10:33.

Essa responsabilidade subjuga os interesses pessoais, frutos de uma postura desumanizada, aos interesses coletivos e, em termos freireanos, deve ser transformada em práxis.

Na obra de Freire, humanização nunca é entendida como assistencialismo irrefletido, que caracteriza a "falsa generosidade". A técnica jamais deveria suplantar o homem, pela simples ação técnica irrefletida, mítica. "Não posso me deixar seduzir pelas tentações míticas, entre elas a da minha escravidão às técnicas, que, sendo elaboradas pelos homens, são suas escravas e não suas senhoras" ${ }^{\prime 30}$ (p. 20), um pensamento perfeitamente adequado às ações de saúde e ideias que permeiam a Saúde da Família, em sua idealização.

Nesse sentido é que Freire valoriza e dá significado ao conhecimento e ao avanço técnico. No entanto, alerta que se trata de desumanização todo ato/postura nos quais sejam suplantados a cultura e os conhecimentos empíricos do povo, na medida em que provêm do ser humano e, como tal, apresentam legitimidade e validade, devendo haver respeito e complementaridade entre os diversos tipos de conhecimentos.

Ao fazer prevalecer um conhecimento sobre os demais, como na desvalorização da cultura popular e suas estratégias de resistência ao modo de produção capitalista, desumanizam-se ambos os grupos de homens, fragmentando a realidade ao se 
valorizar qualquer aspecto sobre os demais da cultura humana, patrimônio legítimo da humanidade ${ }^{30}$. A produção de protocolos e dos formalismos técnicos pauta-se em uma lógica inversa, que destoa da que fundamenta a Saúde da Família no Brasil.

Para Freire, as instâncias da prática profissional possibilitam a segurança do poder dos profissionais diante do restante dos oprimidos. Além disso, a simples aceitação dos protocolos garante uma falsa segurança, que não os obriga a refletir e não permite práxis. Esta se constitui um evento perigoso ao sistema opressor constituído, exigindo coragem para refletir sobre este e para romper com o paradigma da opressão.

Decorrente dessa inversão de valores, origina-se o exercício profissional mecânico. Não crítico, permissivo à ação irrefletida e à dissociação de sua importância histórico-social. Não é ação reflexiva, por basear-se na falsa segurança de que está tudo transcorrendo como deve ser, por se seguir a protocolos e formalismos institucionalizados e cristalizados. Não há necessidade de que o profissional reflita sobre si mesmo e seus semelhantes, e menos ainda sobre o transcurso histórico dos processos sociais em saúde e as possibilidades de intervenção que se apresentam. Funcionando “(...) como uma espécie de cinto de segurança. Daí o homem alienado, inseguro e frustrado, ficar mais na forma que no conteúdo, ver as coisas mais na superfície que em seu interior" ${ }^{\prime \prime 30}$ (p. 3).

Um aspecto levantado por Freire é a necessidade de coragem para a práxis, no sentido de que o homem encontra-se sob um constante processo de opressão na sociedade capitalista. Esse processo faz com que, pela crise que experimentam, os homens pensem-se a si mesmos como problemas. "Descobrem que pouco sabem de si, de seu 'posto no cosmos', e se inquietam por saber mais" ${ }^{30}$ (p. 4)

Ao realizar esse ato de conscientização, tornam-se cada vez mais humanos e percebem-se como tal. Daí humanizam-se. Eis o processo de humanização freireano ${ }^{30}$.

A supervalorização do conhecimento técnico e puramente pragmático, ao priorizar-se o desenvolvimento de habilidades técnicas nos cursos superiores em saúde, pode ser pensada como prática desumanizadora dentro do marco teórico freireano, pois “(...) reduz a prática educativa ao treinamento técnico-científico dos educandos. Ao treinamento e não à formação" ${ }^{35}$ (p. 19). Para Freire, "a necessária formação técnico-científica dos educandos por que se bate a pedagogia crítica não tem nada que ver com a estreiteza tecnicista e cientificista que caracteriza o mero treinamento" ${ }^{\prime \prime 35}$ (p. 20).

A formação em saúde não se distancia dessa realidade. “(...) se nos interessa analisar o compromisso do profissional com a sociedade, teremos que reconhecer que ele, antes de ser profissional, é homem"30 (p. 21).
Dados os desafios contemporâneos do ensino para o SUS, propõe-se as seguintes considerações retiradas do pensamento freireano nas reformulações curriculares como caminho para superação:

- Relação homem-homens: Que o modelo pedagógico empregado propicie espaço tanto para o diálogo entre os acadêmicos e seus contextos de vida, como entre discentes e docentes. O diálogo junto aos usuários deve esvair-se do padrão de simples entrevistas, para o convívio, em um processo de imersão.

- Relação homens-mundo: Há de se superar também o modelo descritivo de problemas dos usuários, em que a visitação em comunidades carentes reveste-se com o forte caráter de única possibilidade pedagógica no transcurso da graduação. Sugere-se que projetos de intervenção sejam oportunizados como atividades curriculares em que, partindo dos problemas socioculturais e econômicos que determinam o processo saúde-doença, os acadêmicos sejam conscientizados e tornem-se agentes de mudanças.

- Superação do estágio técnico-assistencial: Na tentativa de superar o aspecto puramente técnico da formação e ensinar práxis, o ensino de Saúde Coletiva conjunto, tanto teórico como em termos de estágio, há de oportunizar momentos pedagógicos coletivos entre as diversas formações da área da saúde. No entanto, faz-se necessário que esse novo modelo garanta o trabalho coletivo, dialógico e dialético, com a coparticipação e corresponsabilidade das diversas categorias profissionais em sua formação. Do contrário, corre-se o risco de manutenção das relações já estabelecidas no âmbito do PSF, em que o médico, o enfermeiro e o odontólogo apenas convivem no mesmo espaço de trabalho, mas não articulam ações.

Tanto quanto qualquer homem, os profissionais da saúde podem estar inseridos em três relações diferentes de comprometimento com os outros, no universo conceitual freireano. “Como homem, que não pode estar fora de um contexto histórico-social em cujas inter-relações constroem seu eu, é um ser autenticamente comprometido, falsamente 'comprometido' ou impedido de se comprometer verdadeiramente" ${ }^{30}$ (p. 23).

\section{CONSIDERAÇÕES FINAIS}

O pensamento freireano sobre educação, ser humano e mundo é adequado para se repensar os desafios da formação em nível superior para o SUS atual, principalmente na perspectiva ampliada de assistência exigida no âmbito da Saúde da Família. 
Não se questiona a formação técnica e biomédica em si, mas esses pensamentos se opõem à supervalorização desta em detrimento da construção de perfis profissionais que entendam as relações sociais e humanas, tanto quanto a capacidade de intervenção junto a estas no processo de assistência à saúde.

A educação universitária tem possibilidade de oportunizar reflexão ao futuro profissional da saúde sobre seu ato enquanto ser humano, de forma que os profissionais se deparem com seus pacientes em nível técnico de excelência, mas também como seres humanos que cuidam de outros seres humanos.

Para tanto, faz-se necessário que a formação acadêmica delimite espaços para que esses pensamentos possam ser levantados além do treinamento técnico em diagnóstico e intervenção biológica.

Deve ser investigado o modelo pedagógico, não apenas em sua estrutura curricular, mas também na forma como as disciplinas são trabalhadas, priorizando o contínuo exercício da práxis, tanto pelos educandos como pelos educadores.

Há necessidade de imersão no contexto dos cursos universitários para o entendimento de como se dá o processo de ensino-aprendizagem em saúde, para em seguida se propor soluções. E, nesse processo investigativo e de ação, o marco teórico de Paulo Freire tem interessante potencial, haja vista a aproximação de seus princípios e da atual perspectiva sobre saúde, na organização do modelo de atenção da atualidade brasileira, particularmente na Atenção Primária.

\section{REFERÊNCIAS}

1. Cohn A, Elias PE. Saúde no Brasil: políticas e organização de serviços. São Paulo: Cortez/Cedec;1998.

2. Silva PLB. Serviços de saúde: o dilema do SUS na nova década. São Paulo em perspectiva. 2003; 17(1): 69-85.

3. Gerschman S. A democracia inconclusa: um estudo da reforma sanitária brasileira. Rio de Janeiro: Editora Fiocruz; 2004.

4. Campos GWS. O SUS entre a tradição dos Sistemas Nacionais e o modo liberal-privado para organizar o cuidado à saúde. Ciênc saúde coletiva. 2007; 12 (Suppl):1865-1874.

5. Aciole GG. On pedagogical dimensions to citizenship building on social control practice. Interface comunic saúde educ. 2007; 11(23):409-26.

6. Brasil. Ministério da Saúde. Secretaria de Gestão do Trabalho e de Educação na Saúde. Departamento de Educação na Saúde. Política de Educação e Desenvolvimento para o SUS - caminhos para a Educação Permanente em Saúde. Brasília; 2004.

7. Ramos DD, Lima MADS. Acesso e acolhimento aos usuários em uma unidade de saúde de Porto Alegre, Rio Grande do Sul, Brasil. Cad. Saúde Pública. 2003; 19(1):27-34.
8. Alves VS. A health education model for the Family Health Program: towards comprehensive health care and model reorientation. Interface comunic saúde educ. 2005; 9(16): 39-52.

9. Pinheiro R. Práticas de saúde e integralidade: as experiências inovadoras na incorporação e desenvolvimento de novas tecnologias assistenciais de atenção aos usuários no SUS. In: Brasil. Ministério da Saúde. Experiências Inovadoras no SUS: relatos de experiências. Brasília; 2002. p.15.

10. Freire P. Educação e mudança. 28 ${ }^{a}$ ed. São Paulo: Paz e Terra; 1979.

11. Tesser CD. Social medicalization (II): biomedical limits and proposals for primary care clinics. Interface comunic saúde educ. 2006; 10(20): 347-62

12. Cecílio LCO. As necessidades de saúde como conceito estruturante na luta pela integralidade e equidade na atenção em saúde. In: Pinheiro R, Mattos RA, orgs. Os sentidos da integralidade na atenção e no cuidado de saúde. Rio de Janeiro: IMS-Uerj/ Abrasco; 2001. p.113-126.

13. Simões ALA, Rodrigues FR, Tavares DMS, Rodrigues LR. Humanização na saúde: enfoque na atenção primária. Texto \& contexto enferm. 2007; 16(3): 439-44.

14. Moretti-Pires RO, Campos DA. Equipe multiprofissional em Saúde da Família — do documental ao empírico no interior da Amazônia. Rev Bras Ensino Med. 2010; 34(3):379-89.

15. Moretti-Pires RO. Complexidade em Saúde da Família e formação do futuro profissional de saúde. Interface comunic saúde educ. 2009; 13(13):153-166.

16. Brasil. Ministério da Saúde. Ministério da Educação. Pró-Saúde: Programa Nacional de Reorientação da Formação Profissional em Saúde. Brasília: Ministério da Saúde; 2005.

17. Brasil. Ministério da Saúde. Ministério da Educação. A aderência dos cursos de graduação em enfermagem, medicina e odontologia às Diretrizes Curriculares Nacionais. Brasília: Ministério da Saúde; 2006.

18. Brasil. Portaria Interministerial no 1.507 , de 22 de junho de 2007. Institui o Programa de Educação pelo Trabalho para a Saúde - PET-Saúde. Brasília: Diário Oficial da União nº 120; Seção 1, de 25 de junho 2007.

19. Brasil. Ministério da Saúde. Secretaria de Gestão do Trabalho e da Educação na Saúde. Universidade Aberta do Sistema Único de Saúde (UNA-SUS). Disponível em: $<<$ http//:www.saude.gov.br/degets >>. [Acesso em 02 abr. 2010]

20. Santos-Filho SB. Perspectivas da avaliação na Política Nacional de Humanização em Saúde: aspectos conceituais e metodológicos. Ciênc \& Saúde Coletiva. 2007; 12(4):9991010. 
21. Scherer ZAP, Scherer EA. Reflections on nursing teaching in the post-modernity era and the metaphor of a theory-practice gap. Rev Latino-Am Enferm. 2007; 15(3):498-501.

22. Silva $\mathrm{AL}$, Camillo SO. A educação em enfermagem à luz do paradigma da complexidade. Rev Esc Enferm USP. 2007; 41(3):403-10.

23. Cyrino EG, Rizzato ABP. Contribuição à mudança curricular na graduação da Faculdade de Medicina de Botucatu. Rev Bras Saúde Matern Infant. 2004; 4(1): 59-69.

24. Pontes AL, Rego S, Silva Júnior AG. Saber e prática docente na transformação do ensino médico. Rev Bras Educ Med. 2006; 30(2): 66-75

25. Freitas SFT, Kovaleski DF, Boing AF. Desenvolvimento moral em formandos de um curso de odontologia: uma avaliação construtivista. Ciênc \& Saúde Coletiva. 2005. 10(2): 435-62.

26. Araújo ME. Palavras e silêncios na educação superior em odontologia. Ciênc \& Saúde Coletiva. 2006; 11(1):179-182.

27. Gadotti M. Prefácio. In: Freire P. Educação e mudança. $28^{a}$ ed. São Paulo: Paz e Terra; 1979. p. 9-25.

28. Freire P. Educação como prática da liberdade. $4^{\underline{a}}$ ed. Rio de Janeiro: Paz e Terra; 1974.

29. Freire P. Professora sim, tia não. $16^{\underline{a}}$ ed. São Paulo: Olho D’Água; 2006.
30. Freire P. Ação cultural para a liberdade e outros escritos. 10ª ed. São Paulo: Paz e Terra; 2007.

31. Freire P. Pedagogia da autonomia. São Paulo: Editora Paz e Terra; 1999.

32. Freire P. Pedagogia dos sonhos possíveis. São Paulo: Editora UNESP, 2001.

33. Freire P. Pedagogia do oprimido. $43^{\underline{a}}$ ed. São Paulo: Editora Paz e Terra; 1999.

34. Ira S, Freire P. Medo e ousadia. 10 ed. Rio de Janeiro: Paz e Terra; 1986.

35. Freire P. Pedagogia da esperança. Rio de Janeiro: Paz e Terra; 1992.

\section{CONFLITOS DE INTERESSE}

Declarou não haver.

\section{ENDEREÇO PARA CORRESPONDÊNCIA}

Rodrigo Otávio Moretti Pires

Departamento de Saúde Pública -

Centro de Ciências da Saúde - UFSC

Campus Universitário - Trindade

Florianópolis (SC) - CEP 88040-970

Fone: (48) 3721.9388 — ramal 208

Email: rodrigomoretti@ccs.ufsc.br 